\title{
VITAMIN D LEVEL IN IMPAIRED FASTING GLUCOSE AND IMPAIRED GLUCOSE TOLERANCE (PREDIABETIC) PATIENTS
}

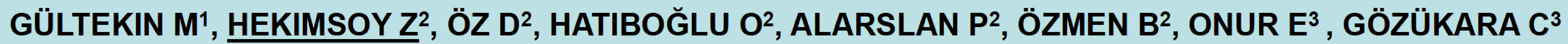

Celal Bayar University Medical Faculty,

${ }^{1}$ Department of Internal Medicine, ${ }^{2}$ Division of Endocrinology and Metabolism, ${ }^{3}$ Departments of Biochemistry, Manisa, TURKEY

Introduction

Material And Methods

\section{Results}

Conclusions

\section{References}

Impaired fasting glucose (IFG) is defined as being present in those whose fasting blood glucose level is consistently elevated above normal, but is not high enough to be considered as having diabetes mellitus. Impaired glucose tolerance (IGT) is defined as being present in those whose second hour plasma glucose level is higher than normal, but is not high enough to be considered as having diabetes mellitus (1). Low serum 25-hydroxyvitamin D (250HD) levels are associated with glucose intolerance, diabetes mellitus, and metabolic syndrome $(2,3)$. To date, the literature is conflicting regarding the relationship between vitamin $D$ levels and prediabetes. Our aims in this study were to evaluate serum 25-hydroxyvitamin $\mathrm{D}$ levels and their association with prediabetic metabolic patterns.

Participants were 220 patients from our endocrine clinic: 85 with isolated IFG, 50 with isolated IGT, 85 with both IFG and IGT, and 80 normoglycemic healthy subjects with similar age, gender, and body mass index (BMI) (Table 1). A detailed history and physical examination of the patients were performed. 25-hydroxyvitamin $\mathrm{D}$, calcium $(\mathrm{Ca})$, phosphorus $(\mathrm{P})$, albumin and parathyroid hormone (PTH) levels were measured. Vitamin $D$ status was assessed as deficient if $25(\mathrm{OH})$ vitamin $\mathrm{D}$ levels were $<20 \mathrm{ng} / \mathrm{mL}$, insufficient if $\geq 20-<30 \mathrm{ng} / \mathrm{mL}$, and sufficient if $\geq 30 \mathrm{ng} / \mathrm{mL}$

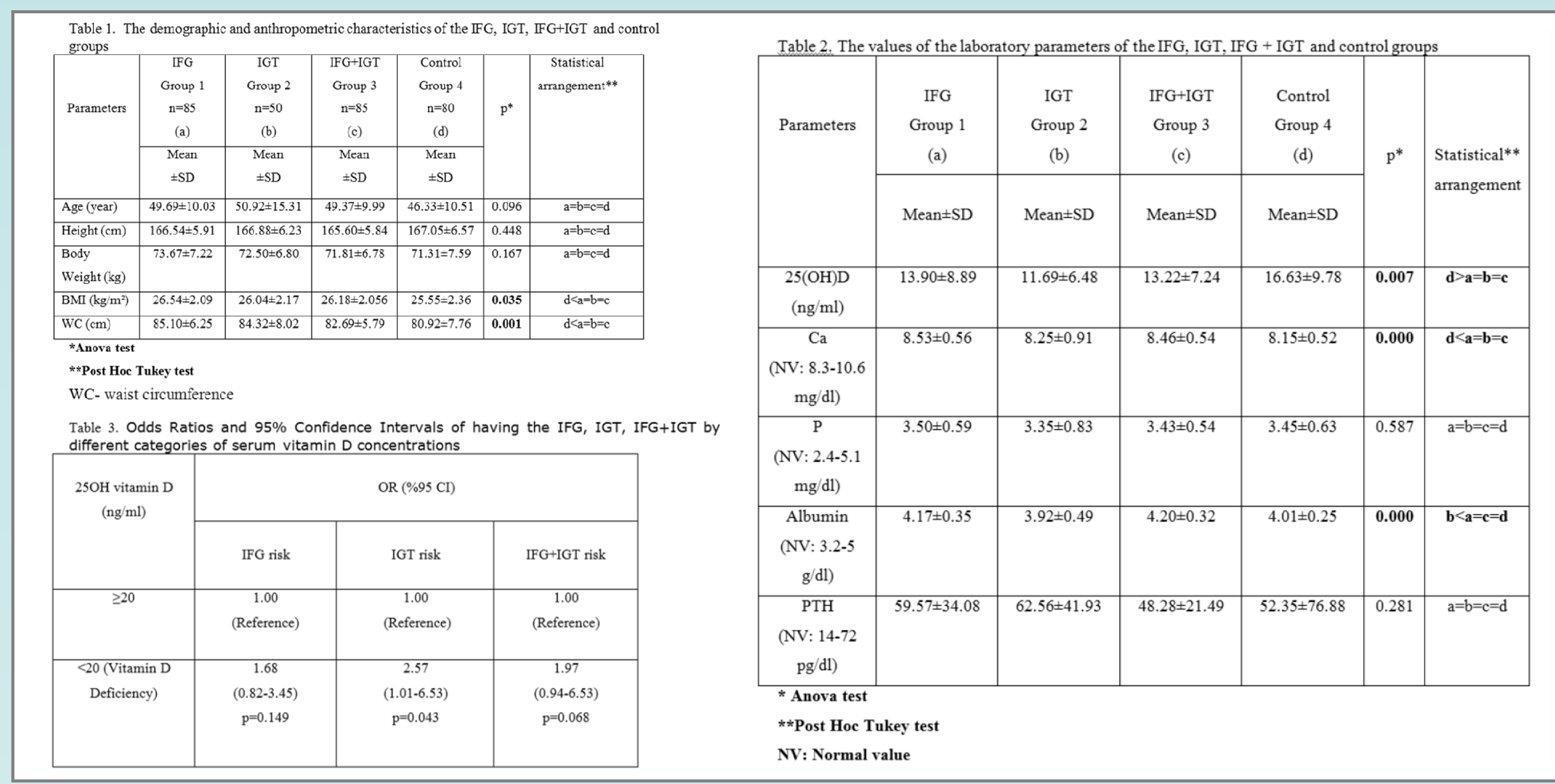

The demographic/anthropometric characteristics and laboratory data of the IFG, IGT, IFG+IGT and control groups were shown in Table 1 and 2 respectively. We found significantly lower $25-$ hydroxyvitamin D levels in the IGT $(11.7 \pm 6.5 \mathrm{ng} / \mathrm{ml})(\mathrm{p}<0.007)$ and IFG+IGT patients $(13.2 \pm 7.2 \mathrm{ng} / \mathrm{ml})$ compared to controls $(16.6 \pm 9.8 \mathrm{ng} / \mathrm{ml})(p<0.047)$. 25-hydroxyvitamin $D$ levels were similar in the control group and IFG group. Significant differences in 25-hydroxyvitamin D levels between the IFG group, IGT group and IFG+IGT group were not found. Lower 25-hydroxy vitamin D levels were associated with a higher risk of IGT (OR 2.57, 95\% Cl 1.01-6.53, p=0.043) (Table 3).

Vitamin D insufficiency and deficiency are associated with IFG, IGT, and combined IFG and IGT. However, the only statistically significant association was that between25-hydroxyvitamin D levels and IGT.

1. Tabák AG, Herder C, Rathmann W, Brunner EJ, Kivimäki M. Prediabetes: a high-risk state for diabetes development. Lancet 2012;379: 2279-2290.

2. Petersen JL, McGuire DK. Impaired glucose tolerance and impaired fasting glucose-a review of diagnosis, clinical implications and management. Diab Vasc Dis Res 2005;2: 9-15.

3. Tsur A, Feldman BS, Feldhammer I, Hoshen MB, Leibowitz G, Balicer RD. Decreased serum concentrations of 25-Hydroxycholecalciferol are associated with increased risk of progression to impaired fasting glucose and diabetes. Diabetes Care 2013;36(5): 1361-1367. 